\title{
FIXED POINTS OF ALMOST PRESIĆ OPERATORS BY A $k$-STEP ITERATIVE METHOD
}

BY

\author{
MĂDĂLINA PĂCURAR
}

\begin{abstract}
The convergence of a $k$-step iterative method for a new general class of Presić type operators in a metric space setting is proved. Information on the rate of convergence is provided. The data dependence of the fixed points is also studied.

Mathematics Subject Classification 2000: 47H10, 54H25.

Key words: almost contraction, strict almost contraction, Presić type operator, fixed point, $k$-step iterative method, rate of convergence, data dependence.
\end{abstract}

\section{Introduction}

In paper [3] (see also [4]) a very interesting class of weakly Picard operators was introduced, namely that of weak contractions, later renamed as almost contractions, due to certain behavioral similarities to Banach contractions. Since then tens of papers have appeared, containing different approaches, applications and generalizations, see for example [10], [11], [12]-[24].

An interesting new direction of generalization is suggested by similar approaches related to other classes of general contractive operators, as in [26], [21], [7]. These papers were inspired by the results due to PREsić [25], who proved the convergence of a $k$-step iterative method to the unique fixed point of an operator $f: X^{k} \rightarrow X$ satisfying:

$$
d\left(f\left(x_{0}, \ldots, x_{k-1}\right), f\left(x_{1}, \ldots, x_{k}\right)\right) \leq \sum_{i=1}^{k} \alpha_{i} d\left(x_{i-1}, x_{i}\right),
$$


for all $x_{0}, \ldots, x_{k} \in X$, where $(X, d)$ is a complete metric space, $k$ is a positive integer and $\alpha_{1}, \alpha_{2}, \ldots, \alpha_{k} \in \mathbb{R}_{+}$are such that $\sum_{i=1}^{k} \alpha_{i}=\alpha<1$.

These approaches are motivated by the currently increasing interest in the study of nonlinear difference equations, which model different problems appearing in economics, biology, ecology, genetics, psychology, sociology, probability theory and others (see for example [5], [6], [8], [9], [13], [14], [15], [19], [27], [28], [29] and the references therein).

Considering the $k$-th order nonlinear difference equation

$$
x_{n+k}=f\left(x_{n}, \ldots, x_{n+k-1}\right), n \in \mathbb{N},
$$

with the initial values $x_{0}, \ldots, x_{k-1} \in X$, where $(X, d)$ is a metric space, $k \in \mathbb{N}, k \geq 1$ and $f: X^{k} \rightarrow X$, we can study it by means of fixed point theory in view of the fact that $x^{*} \in X$ is a solution of (1.1) iff $x^{*}$ is a fixed point of $f$, that is,

$$
x^{*}=f\left(x^{*}, \ldots, x^{*}\right) .
$$

This is the direction we shall follow in the present paper, by proving the convergence of the $k$-step iterative method (1.1) in the case of a new general class of Presić type operators, also providing information regarding the rate of convergence.

\section{Preliminaries}

In [3] the following was introduced:

Definition 2.1. Let $(X, d)$ be a metric space. An operator $f: X \rightarrow X$ is called almost contraction if there exist two constants $\delta \in[0,1)$ and $L \geq 0$ such that:

$$
d(f(x), f(y)) \leq \delta d(x, y)+L d(y, f(x)),
$$

for any $x, y \in X$.

In Theorem 1 [3] it is shown that the almost contractions are weakly Picard operators. In the same paper, Theorem 2 adds the following condition on the almost contractions, thus obtaining the uniqueness of the fixed point:

$$
d(f(x), f(y)) \leq \delta_{u} d(x, y)+L_{u} d(x, f(x)),
$$

for any $x, y \in X$, where $\delta_{u} \in[0,1)$ and $L_{u} \geq 0$ are constants. Inspired by this result, in [23] we considered: 
Definition 2.2. Let $(X, d)$ be a metric space. An operator $f: X \rightarrow X$ is called strict almost contraction if it satisfies both condition (AC) and (AC-U), with some real constants $\delta \in[0,1), L \geq 0$ and $\delta_{u} \in[0,1), L_{u} \geq 0$, respectively.

Having in view Definition 2.2, we can restate (part of) Theorem 2 from [3] as follows (see also [23]):

Theorem 2.1. Let $(X, d)$ be a complete metric space and $f: X \rightarrow X$ a strict almost contraction with constants $\delta \in[0,1), L \geq 0$ and $\delta_{u} \in[0,1)$, $L_{u} \geq 0$, respectively.

Then $f$ has a unique fixed point, say $x^{*}$, that can be approximated by means of the Picard iteration $\left\{x_{n}\right\}_{n \geq 0}$ of $f$, starting from any $x_{0} \in X$.

Remark 2.1. In [22] it is shown that the following condition (B), introduced in [1], is an equivalent definition of strict almost contractions:

(B) $d(f(x), f(y)) \leq \delta_{B} d(x, y)$

$$
+L_{B} \min \{d(x, f(x)), d(y, f(y)), d(x, f(y)), d(y, f(x))\},
$$

for any $x, y \in X$ and some constants $\delta_{B} \in[0,1)$ and $L_{B} \geq 0$.

In order to prove our main result we shall also need the following lemmas:

Lemma 2.1 ([25]). Let $k \in \mathbb{N}, k \neq 0$ and $\alpha_{1}, \alpha_{2}, \ldots, \alpha_{k} \in \mathbb{R}_{+}$such that $\sum_{i=1}^{k} \alpha_{i}=\alpha<1$. If $\left\{\Delta_{n}\right\}_{n \geq 1}$ is a sequence of positive numbers satisfying

$$
\Delta_{n+k} \leq \alpha_{1} \Delta_{n}+\alpha_{2} \Delta_{n+1}+\ldots+\alpha_{k} \Delta_{n+k-1}, n \geq 1
$$

then there exist $L>0$ and $\theta \in(0,1)$ such that $\Delta_{n} \leq L \cdot \theta^{n}$, for all $n \geq 1$.

Lemma $2.2([2])$. Let $\left\{a_{n}\right\}_{n \geq 0},\left\{b_{n}\right\}_{n \geq 0}$ be two sequences of positive real numbers and $q \in(0,1)$ such that $a_{n+1} \leq q a_{n}+b_{n}, n \geq 0$ and $b_{n} \rightarrow 0$ as $n \rightarrow \infty$. Then $\lim _{n \rightarrow \infty} a_{n}=0$.

\section{The main result}

Having in view the considerations above, we introduce: 
Definition 3.1. Let $(X, d)$ be a metric space and $k$ a positive integer. An operator $f: X^{k} \rightarrow X$ for which there exist some real constants $\delta_{1}, \ldots, \delta_{k} \in \mathbb{R}_{+}$with $\sum_{i=1}^{n} \delta_{i}=\delta<1$ and $L \geq 0$ such that:

$$
d\left(f\left(x_{0}, \ldots, x_{k-1}\right), f\left(x_{1}, \ldots, x_{k}\right)\right) \leq \sum_{i=1}^{k} \delta_{i} d\left(x_{i-1}, x_{i}\right)+\bar{M}\left(x_{0}, x_{k}\right)
$$

where

$$
\begin{aligned}
& \bar{M}\left(x_{0}, x_{k}\right)=L \min \left\{d\left(x_{0}, f\left(x_{0}, \ldots, x_{0}\right)\right), d\left(x_{k}, f\left(x_{k}, \ldots, x_{k}\right)\right),\right. \\
& \left.\quad d\left(x_{0}, f\left(x_{k}, \ldots, x_{k}\right)\right), d\left(x_{k}, f\left(x_{0}, \ldots, x_{0}\right)\right), d\left(x_{k}, f\left(x_{0}, x_{1}, \ldots, x_{k-1}\right)\right)\right\},
\end{aligned}
$$

for any $x_{0}, \ldots, x_{k} \in X$, is called almost Presić operator.

Remark 3.1. It is easy to check that for $k=1$ the terms $d\left(x_{k}, f\left(x_{0}, \ldots\right.\right.$, $\left.\left.x_{0}\right)\right)$ and $d\left(x_{k}, f\left(x_{0}, x_{1}, \ldots, x_{k-1}\right)\right)$ actually coincide, and Definition 3.1 reduces to the equivalent definition of strict almost contractions expressed by inequality (B).

Remark 3.2. For $L=0$, from the above condition (AP) we obtain condition $(\mathrm{P})$ which defines Presić operators.

Remark 3.3. Considering $f$ as in Definition 3.1 and its associate operator $F: X \rightarrow X, F(x)=f(x, \ldots, x)$, for any $x_{0}, \ldots, x_{k} \in X$ we have that

$$
\begin{aligned}
& \bar{M}\left(x_{0}, x_{k}\right)=L \min \left\{d\left(x_{0}, f\left(x_{0}, \ldots, x_{0}\right)\right), d\left(x_{k}, f\left(x_{k}, \ldots, x_{k}\right)\right),\right. \\
& \left.d\left(x_{0}, f\left(x_{k}, \ldots, x_{k}\right)\right), d\left(x_{k}, f\left(x_{0}, \ldots, x_{0}\right)\right), d\left(x_{k}, f\left(x_{0}, x_{1}, \ldots, x_{k-1}\right)\right)\right\} \\
& \leq L \min \left\{d\left(x_{0}, f\left(x_{0}, \ldots, x_{0}\right)\right), d\left(x_{k}, f\left(x_{k}, \ldots, x_{k}\right)\right), d\left(x_{0}, f\left(x_{k}, \ldots, x_{k}\right)\right),\right. \\
& \left.d\left(x_{k}, f\left(x_{0}, \ldots, x_{0}\right)\right)\right\} \\
& =L \min \left\{d\left(x_{0}, F\left(x_{0}\right)\right), d\left(x_{k}, F\left(x_{k}\right)\right), d\left(x_{0}, F\left(x_{k}\right)\right), d\left(x_{k}, F\left(x_{0}\right)\right)\right\} .
\end{aligned}
$$

In the following we shall prove the convergence of the Presic type method constructed by means of almost Presić operators, also providing the rate of convergence for this iterative procedure.

Theorem 3.1. Let $(X, d)$ be a complete metric space, $k$ a positive integer and $f: X^{k} \rightarrow X$ an almost Presić operator with constants $\delta_{1}, \ldots, \delta_{k} \in$ $\mathbb{R}_{+}, \sum_{i=1}^{k} \delta_{i}=\delta<1$ and $L \geq 0$. Then: 
1) $f$ has a unique fixed point, say $x^{*} \in X$;

2) the sequence $\left\{y_{n}\right\}_{n \geq 0}$ defined by

$$
y_{n}=f\left(y_{n-1}, \ldots, y_{n-1}\right), n \geq 1,
$$

converges to $x^{*}$ for any starting point $y_{0} \in X$;

3) the sequence $\left\{x_{n}\right\}_{n \geq 0}$ defined by $x_{0}, \ldots, x_{k-1} \in X$ and (1.1) also converges to $x^{*}$, with a rate estimated by

$$
d\left(x_{n}, x^{*}\right) \leq E_{n-k}+\delta d\left(x_{n-1}, x^{*}\right), n \geq 0,
$$

where

$$
\begin{aligned}
E_{n-k}: & =\delta_{1} d\left(x_{n-k}, x_{n-k+1}\right)+\left(\delta_{1}+\delta_{2}\right) d\left(x_{n-k+1}, x_{n-k+2}\right) \\
& +\ldots+\left(\delta_{1}+\ldots+\delta_{k-1}\right) d\left(x_{n-2}, x_{n-1}\right)
\end{aligned}
$$

Proof. 1), 2) We consider the associate operator $F: X \rightarrow X$ defined by $F(x)=f(x, \ldots, x), x \in X$. For any $x, y \in X$ we have that:

$$
\begin{aligned}
& d(F(x), F(y))=d(f(x, \ldots, x), f(y, \ldots, y)) \\
& \quad \leq d(f(x, \ldots, x), f(x, \ldots, x, y))+\ldots+d(f(x, y, \ldots, y), f(y, \ldots, y)) .
\end{aligned}
$$

By (AP) and Remark 3.3, this implies:

$$
\begin{aligned}
& d(F(x), F(y)) \leq \delta_{k} d(x, y) \\
& \quad+L \min \left\{d(x, F(x)), d(y, F(y)), d(x, F(y)), d(y, F(x))+\delta_{k-1} d(x, y)\right. \\
& \quad+L \min \left\{d(x, F(x)), d(y, F(y)), d(x, F(y)), d(y, F(x))+\ldots+\delta_{1} d(x, y)\right. \\
& \quad+L \min \{d(x, F(x)), d(y, F(y)), d(x, F(y)), d(y, F(x)),
\end{aligned}
$$

which is equivalent to

$$
\begin{aligned}
d(F(x), F(y)) & \leq \delta d(x, y) \\
& +k L \min \{d(x, F(x)), d(y, F(y)), d(x, F(y)), d(y, F(x)),
\end{aligned}
$$

that is, $F$ satisfies condition (B) above, with constants $\delta \in[0,1)$ and $k L \geq 0$, so by Remark 2.1 and Theorem 2.1 above it has a unique fixed point, say $x^{*} \in X$, that can be obtained as the limit of the successive approximations of $F$ starting from any $x \in X$. 
Having in view the definition of $F$ and considering the sequence of successive approximations of $F,\left\{y_{n}\right\}_{n \geq 0}$ defined by

$$
y_{n}=F\left(y_{n-1}\right)=f\left(y_{n-1}, y_{n-1}, \ldots, y_{n-1}\right), n \geq 1,
$$

this leads exactly to conclusions 1) and 2).

3) Now let us prove that the $k$-step iterative method $\left\{x_{n}\right\}_{n \geq 0}$ given by (1.1) converges to $x^{*}$ as well.

Let $x_{0}, \ldots, x_{k-1} \in X$ and $x_{n}=f\left(x_{n-k}, \ldots, x_{n-1}\right), n \geq k$. Then:

$$
\begin{aligned}
d\left(x_{k}, x^{*}\right)= & d\left(f\left(x_{0}, \ldots, x_{k-1}\right), f\left(x^{*}, \ldots, x^{*}\right)\right) \\
\leq & d\left(f\left(x_{0}, \ldots, x_{k-1}\right), f\left(x_{1}, \ldots, x_{k-1}, x^{*}\right)\right) \\
& +\ldots+d\left(f\left(x_{k-1}, x^{*}, \ldots, x^{*}\right), f\left(x^{*}, \ldots, x^{*}\right)\right) .
\end{aligned}
$$

When applying (AP) and Remark 3.3 for each term of the sum on the right hand side of (3.3), we get:

$$
\begin{aligned}
& d\left(f\left(x_{0}, \ldots, x_{k-1}\right), f\left(x_{1}, \ldots, x_{k-1}, x^{*}\right)\right) \\
& \quad \leq \delta_{1} d\left(x_{0}, x_{1}\right)+\ldots+\delta_{k-1} d\left(x_{k-2}, x_{k-1}\right)+\delta_{k} d\left(x_{k-1}, x^{*}\right) \\
& \quad+L \min \left\{d\left(x_{0}, F\left(x_{0}\right)\right), d\left(x^{*}, F\left(x^{*}\right)\right), d\left(x_{0}, F\left(x^{*}\right)\right), d\left(x^{*}, F\left(x_{0}\right)\right)\right\}
\end{aligned}
$$

and so on,

$$
\begin{aligned}
& d\left(f\left(x_{k-2}, x_{k-1}, x^{*}, \ldots, x^{*}\right), f\left(x_{k-1}, x^{*}, \ldots, x^{*}\right)\right) \\
& \leq \delta_{1} d\left(x_{k-2}, x_{k-1}\right)+\delta_{2} d\left(x_{k-1}, x^{*}\right)+ \\
& +L \min \left\{d\left(x_{k-2}, F\left(x_{k-2}\right)\right), d\left(x^{*}, F\left(x^{*}\right)\right), d\left(x_{k-2}, F\left(x^{*}\right)\right), d\left(x^{*}, F\left(x_{k-2}\right)\right)\right\}
\end{aligned}
$$

respectively

$$
\begin{aligned}
& d\left(f\left(x_{k-1}, x^{*}, \ldots, x^{*}\right), f\left(x^{*}, \ldots, x^{*}\right)\right) \leq \delta_{1} d\left(x_{k-1}, x^{*}\right) \\
& +L \min \left\{d\left(x_{k-1}, F\left(x_{k-1}\right)\right), d\left(x^{*}, F\left(x^{*}\right)\right), d\left(x_{k-1}, F\left(x^{*}\right)\right), d\left(x^{*}, F\left(x_{k-1}\right)\right)\right\} .
\end{aligned}
$$

As $d\left(x^{*}, F\left(x^{*}\right)\right)=0,(3.3)$ finally leads to

$$
\begin{aligned}
d\left(x_{k}, x^{*}\right) & \leq \delta_{1} d\left(x_{0}, x_{1}\right)+\left(\delta_{1}+\delta_{2}\right) d\left(x_{1}, x_{2}\right) \\
& +\ldots+\left(\delta_{1}+\ldots+\delta_{k-1}\right) d\left(x_{k-2}, x_{k-1}\right)+\delta d\left(x_{k-1}, x^{*}\right)
\end{aligned}
$$

Since $k$ is a fixed positive integer, so are the coefficients $\delta_{1}, \delta_{1}+\delta_{2}, \ldots$, $\delta_{1}+\ldots+\delta_{k-1}, \delta$. Therefore we may denote:

$$
E_{0}:=\delta_{1} d\left(x_{0}, x_{1}\right)+\left(\delta_{1}+\delta_{2}\right) d\left(x_{1}, x_{2}\right)+\ldots+\left(\delta_{1}+\ldots+\delta_{k-1}\right) d\left(x_{k-2}, x_{k-1}\right),
$$


so (3.4) can be written as $d\left(x_{k}, x^{*}\right) \leq E_{0}+\delta d\left(x_{k-1}, x^{*}\right)$. Similarly we get that

$$
\begin{aligned}
d\left(x_{k+1}, x^{*}\right) \leq & \delta_{1} d\left(x_{1}, x_{2}\right)+\left(\delta_{1}+\delta_{2}\right) d\left(x_{2}, x_{3}\right) \\
& +\ldots+\left(\delta_{1}+\ldots+\delta_{k-1}\right) d\left(x_{k-1}, x_{k}\right)+\delta d\left(x_{k}, x^{*}\right) .
\end{aligned}
$$

Denoting

$$
E_{1}:=\delta_{1} d\left(x_{1}, x_{2}\right)+\left(\delta_{1}+\delta_{2}\right) d\left(x_{2}, x_{3}\right)+\ldots+\left(\delta_{1}+\ldots+\delta_{k-1}\right) d\left(x_{k-1}, x_{k}\right),
$$

inequality $(3.5)$ can be written as $d\left(x_{k+1}, x^{*}\right) \leq E_{1}+\delta d\left(x_{k}, x^{*}\right)$. In this manner we obtain, for $n \geq k$, that

$$
d\left(x_{n}, x^{*}\right) \leq \delta_{1} d\left(x_{n-k}, x_{n-k+1}\right)+\left(\delta_{1}+\delta_{2}\right) d\left(x_{n-k+1}, x_{n-k+2}\right)
$$

Denoting

$$
\begin{aligned}
E_{n-k}:= & \delta_{1} d\left(x_{n-k}, x_{n-k+1}\right)+\left(\delta_{1}+\delta_{2}\right) d\left(x_{n-k+1}, x_{n-k+2}\right) \\
& +\ldots+\left(\delta_{1}+\ldots+\delta_{k-1}\right) d\left(x_{n-2}, x_{n-1}\right),
\end{aligned}
$$

inequality (3.6) becomes

$$
d\left(x_{n}, x^{*}\right) \leq E_{n-k}+\delta d\left(x_{n-1}, x^{*}\right), \text { for } n \geq k .
$$

In order to apply Lemma 2.2 , we still have to prove that the sequence $\left\{E_{n}\right\}_{n \geq 0}$ given by

$$
\begin{aligned}
E_{n}= & \delta_{1} d\left(x_{n}, x_{n+1}\right)+\left(\delta_{1}+\delta_{2}\right) d\left(x_{n+1}, x_{n+2}\right) \\
& +\ldots+\left(\delta_{1}+\ldots+\delta_{k-1}\right) d\left(x_{n+k-2}, x_{n+k-1}\right), \quad n \geq 0
\end{aligned}
$$

converges to 0 as $n \rightarrow \infty$.

For $n \geq k$ we have:

$$
d\left(x_{n}, x_{n+1}\right)=d\left(f\left(x_{n-k}, \ldots, x_{n-1}\right), f\left(x_{n-k+1}, \ldots, x_{n}\right)\right) .
$$

By (AP) this yields:

$$
\begin{aligned}
d\left(x_{n}, x_{n+1}\right) \leq & \delta_{1} d\left(x_{n-k}, x_{n-k+1}\right)+\ldots+\delta_{k} d\left(x_{n-1}, x_{n}\right) \\
+ & L \min \left\{d\left(x_{n-k}, F\left(x_{n-k}\right)\right), d\left(x_{n}, F\left(x_{n}\right)\right), d\left(x_{n-k}, F\left(x_{n}\right)\right),\right. \\
& \left.d\left(x_{n}, F\left(x_{n-k}\right)\right), d\left(x_{n}, f\left(x_{n-k}, \ldots, x_{n-1}\right)\right)\right\} .
\end{aligned}
$$


As $d\left(x_{n}, f\left(x_{n-k}, \ldots, x_{n-1}\right)\right)=0,(3.9)$ finally leads to

$$
d\left(x_{n}, x_{n+1}\right) \leq \delta_{1} d\left(x_{n-k}, x_{n-k+1}\right)+\ldots+\delta_{k} d\left(x_{n-1}, x_{n}\right) \text {, for } n \geq k .
$$

According to Lemma 2.1, this implies the existence of $\theta \in(0,1)$ and $K \geq 0$ such that $d\left(x_{n}, x_{n+1}\right) \leq K \theta^{n+k}, n \geq 0$. Since $k$ is fixed, it is immediate that the sequence $\left\{E_{n}\right\}_{n \geq 0}$ given by (3.8) converges to 0 as $n \rightarrow \infty$.

Denoting $\bar{E}_{n}:=E_{n-k},(3.7)$ is written as:

$$
d\left(x_{n}, x^{*}\right) \leq \bar{E}_{n}+\delta d\left(x_{n-1}, x^{*}\right) .
$$

Now taking $a_{n}=d\left(x_{n}, x^{*}\right), n \geq k$ and $b_{n}=\bar{E}_{n}, n \geq k$ in Lemma 2.2, by (3.10) it follows that $d\left(x_{n}, x^{*}\right) \rightarrow 0$ as $n \rightarrow \infty$, that is, the multi-step iterative method $\left\{x_{n}\right\}_{n \geq 0}$ converges to $x^{*}$, the unique fixed point of $f$.

Remark 3.4. Note that for $L=0$ from Theorem 3.1 we get the result due to PREsić [25], while for $k=1$ Theorem 2 in [3] for strict almost contractions in metric spaces is obtained.

For $k=1$ and $L=0$, Theorem 3.1 reduces to the Contraction Mapping Principle of Banach.

Regarding the data dependence of the fixed points we have:

Theorem 3.2. Let $(X, d)$ be a complete metric space, $k$ a positive integer, $f: X^{k} \rightarrow X$ as in Theorem 3.1 and $g: X^{k} \rightarrow X$ satisfying:

i) $g$ has at least a fixed point $x_{g}^{*} \in X$;

ii) there exists $\eta>0$ such that for any $x \in X, d(f(x, \ldots, x), g(x, \ldots, x)) \leq \eta$.

Then $d\left(x_{f}^{*}, x_{g}^{*}\right) \leq \frac{\eta}{1-\delta}$, where $x_{f}^{*}$ is the unique fixed point of $f$.

Proof. Theorem 3.1 above guarantees the existence and uniqueness of the fixed point of $f$, say $x_{f}^{*} \in X$. We have:

$$
\begin{aligned}
d\left(x_{f}^{*}, x_{g}^{*}\right) & =d\left(f\left(x_{f}^{*}, \ldots, x_{f}^{*}\right), g\left(x_{g}^{*}, \ldots, x_{g}^{*}\right)\right) \\
& \leq d\left(f\left(x_{f}^{*}, \ldots, x_{f}^{*}\right), f\left(x_{g}^{*}, \ldots, x_{g}^{*}\right)\right)+d\left(f\left(x_{g}^{*}, \ldots, x_{g}^{*}\right), g\left(x_{g}^{*}, \ldots, x_{g}^{*}\right)\right) .
\end{aligned}
$$

By $i$ ) this yields

$$
\begin{aligned}
d\left(x_{f}^{*}, x_{g}^{*}\right) & \leq \eta+d\left(f\left(x_{f}^{*}, \ldots, x_{f}^{*}\right), f\left(x_{f}^{*}, \ldots, x_{f}^{*}, x_{g}^{*}\right)\right) \\
& +\ldots+d\left(f\left(x_{f}^{*}, x_{g}^{*}, \ldots, x_{g}^{*}\right), f\left(x_{g}^{*}, \ldots, x_{g}^{*}\right)\right) .
\end{aligned}
$$


Estimating by (AP) the distances in the right hand side of the above inequality (3.11) and applying for each of them Remark 3.3, we obtain that:

$$
\begin{aligned}
d\left(x_{f}^{*}, x_{g}^{*}\right) & \leq \eta+\left[\delta_{k} d\left(x_{f}^{*}, x_{g}^{*}\right)+\widetilde{M}\left(x_{f}^{*}, x_{g}^{*}\right)\right] \\
& +\ldots+\left[\delta_{1} d\left(x_{f}^{*}, x_{g}^{*}\right)+\widetilde{M}\left(x_{f}^{*}, x_{g}^{*}\right)\right]
\end{aligned}
$$

where

$$
\widetilde{M}\left(x_{f}^{*}, x_{g}^{*}\right)=\min \left\{d\left(x_{f}^{*}, F\left(x_{f}^{*}\right)\right), d\left(x_{g}^{*}, F\left(x_{g}^{*}\right)\right), d\left(x_{f}^{*}, F\left(x_{g}^{*}\right)\right), d\left(x_{g}^{*}, F\left(x_{f}^{*}\right)\right)\right\} .
$$

Since $x_{f}^{*}$ and $x_{g}^{*}$ are fixed points of $f$ and $g$, respectively, it follows that $\widetilde{M}\left(x_{f}^{*}, x_{g}^{*}\right)=0$. Thus inequality (3.12) becomes $d\left(x_{f}^{*}, x_{g}^{*}\right) \leq \eta+\delta d\left(x_{f}^{*}, x_{g}^{*}\right)$, so finally $d\left(x_{f}^{*}, x_{g}^{*}\right) \leq \frac{\eta}{1-\delta}$, a relation very similar to the case of Presić operators.

Using this result we also proved a related Nadler type result in [23].

\section{Application}

Similar to the result mentioned in Remark 2.1 (see [22] for a detailed proof), it is elementary to prove the following:

Lemma 4.1. Let $(X, d)$ be a metric space, $k$ a positive integer and $f: X^{k} \rightarrow X$. Then $f$ is an almost Presić operator, that is, it satisfies condition $(A P)$, if and only if the following conditions are simultaneously fulfilled:

(AP1) there exist $\delta_{1}, \ldots, \delta_{k} \in \mathbb{R}_{+}$with $\sum_{i=1}^{k} \delta_{i}<1$ and $L \geq 0$ such that:

$$
\begin{aligned}
& d\left(f\left(x_{0}, \ldots, x_{k-1}\right), f\left(x_{1}, \ldots, x_{k}\right)\right) \\
& \leq \sum_{i=1}^{k} \delta_{i} d\left(x_{i-1}, x_{i}\right)+L d\left(x_{k}, f\left(x_{0}, \ldots, x_{0}\right)\right),
\end{aligned}
$$

for any $x_{0}, x_{1}, \ldots, x_{k} \in X$;

(AP2) there exist $\bar{\delta}_{1}, \ldots, \bar{\delta}_{k} \in \mathbb{R}_{+}$with $\sum_{i=1}^{k} \bar{\delta}_{i}<1$ and $\bar{L} \geq 0$ such that:

$$
\begin{aligned}
& d\left(f\left(x_{0}, \ldots, x_{k-1}\right), f\left(x_{1}, \ldots, x_{k}\right)\right) \\
& \leq \sum_{i=1}^{k} \bar{\delta}_{i} d\left(x_{i-1}, x_{i}\right)+\bar{L} d\left(x_{0}, f\left(x_{0}, \ldots, x_{0}\right)\right),
\end{aligned}
$$

for any $x_{0}, x_{1}, \ldots, x_{k} \in X$; 
(AP3) there exist $\widetilde{\delta}_{1}, \ldots, \widetilde{\delta}_{k} \in \mathbb{R}_{+}$with $\sum_{i=1}^{k} \widetilde{\delta}_{i}<1$ and $\widetilde{L} \geq 0$ such that:

$$
\begin{aligned}
& d\left(f\left(x_{0}, \ldots, x_{k-1}\right), f\left(x_{1}, \ldots, x_{k}\right)\right) \\
& \leq \sum_{i=1}^{k} \widetilde{\delta}_{i} d\left(x_{i-1}, x_{i}\right)+\widetilde{L} d\left(x_{k}, f\left(x_{0}, \ldots, x_{k-1}\right)\right),
\end{aligned}
$$

for any $x_{0}, x_{1}, \ldots, x_{k} \in X$.

Having in view Lemma 4.1, practically it suffices to verify that a given operator satisfies conditions (AP1), (AP2) and (AP3) for some proper constants, in order to prove that it is actually an almost Presić operator, as dealing with condition (AP) sometimes implies a more complicated analysis.

Such an approach has lead us to the following:

Example 4.1. Let $f:[0,1] \times[0,1] \rightarrow[0,1]$ defined by:

$$
f(x)= \begin{cases}\frac{x+y}{8}, & (x, y) \in[0,1) \times[0,1) \\ \frac{1}{3}, & (x, y) \in 1 \times[0,1] \cup[0,1) \times 1 .\end{cases}
$$

Then:

1) $f$ is an almost Presić operator, satisfying condition (AP1) with $\delta_{1}=\frac{5}{8}$, $\delta_{2}=\frac{2}{8}, L=\frac{3}{8}$, condition (AP2) with $\bar{\delta}_{1}=\frac{3}{8}, \bar{\delta}_{2}=\frac{3}{8}, \bar{L}=\frac{1}{6}$ and condition (AP3) with $\widetilde{\delta}_{1}=\frac{5}{8}, \widetilde{\delta}_{2}=\frac{2}{8}, \widetilde{L}=\frac{3}{8}$;

2) $f$ is not a Presić operator;

3) $f$ is not a Presić-Ćirić operator (see [7], [23]);

4) $f$ is not a Presić-Rus operator (see [26], [23]);

5) $f$ is not a Presić-Kannan operator (see [21], [23]).

This elementary example shows the new class of almost Presić operators is not included in either of the above mentioned Presic type classes of operators known in literature.

Acknowledgments. I am very grateful to the inspired remarks and suggestions of the referee, which have contributed to completing and reshaping the paper.

This work was supported by CNCSIS-UEFISCSU, project number PNIIIDEI $2366 / 2008$. 


\section{REFERENCES}

1. Babu, G.V.R.; Sandhya, M.L.; Kameswari, M.V.R. - A note on a fixed point theorem of Berinde on weak contractions, Carpathian J. Math., 24 (2008), 8-12.

2. Berinde, V. - Contracţii Generalizate şi Aplicaţii, Editura Cub Press 22, Baia Mare, 1997.

3. BERINDE, V. - Approximating fixed points of weak contractions using the Picard iteration, Nonlinear Anal. Forum, 9 (2004), 43-53.

4. Berinde, V. - Iterative Approximation of Fixed Points, Lecture Notes in Mathematics, 1912, Springer, Berlin, 2007.

5. Camouzis, E.; Chatterjee, E.; Ladas, G. - On the dynamics of $x_{n+1}=\left(\delta x_{n-2}+\right.$ $\left.x_{n-3}\right) /\left(A+x_{n-3}\right)$, J. Math. Anal. Appl., 331 (2007), 230-239.

6. Chen, Yong-Zhuo - A Prešić type contractive condition and its applications, Nonlinear Anal., 71 (2009), 2012-2017.

7. Cirić, L.B.; Presić, S.B. - On Presić type generalization of the Banach contraction mapping principle, Acta Math. Univ. Comenian. (N.S.), 76 (2007), 143-147.

8. DeVault, R.; Dial, G.; Kocic, V.L.; Ladas, G. - Global behavior of solutions of $x_{n+1}=a x_{n}+f\left(x_{n}, x_{n-1}\right)$, J. Differ. Equations Appl., 3 (1998), 311-330.

9. El-Metwally, H.; Grove, E.A.; Ladas, G.; Levins, R.; Radin, M. - On the difference equation $x_{n+1}=\alpha+\beta x_{n-1} e^{-x_{n}}$, Nonlinear Anal., 47 (2001), 4623-4634

10. Kamran, T. - Multivalued f-weakly Picard mappings, Nonlinear Anal., 67 (2007), 2289-2296.

11. Kamran, T.; CAKIĆ, N.-Hybrid tangential property and coincidence point theorems, Fixed Point Theory, 9 (2008), 487-496.

12. Kiran, Q.; Kamran, T. - Nadler's type principle with high order of convergence, Nonlinear Anal., 69 (2008), 4106-4120.

13. Kocić, V.L. - A note on the non-autonomous Beverton-Holt model, J. Difference Equ. Appl., 11 (2005), 415-422.

14. Kocić, V.L.; Ladas, G. - Global Asymptotic Behavior of Nonlinear Difference Equations of Higher Order with Applications, Kluwer Academic Publishers, Dordrecht, 1993.

15. Kuruklis, S.A. - The asymptotic stability of $x_{n+1}-a x_{n}+b x_{n-k}=0$, J. Math. Anal. Appl., 188 (1994), 719-731.

16. NADleR, S.B. - Sequences of contractions and fixed points, Pacific J. Math., 27 (1968), 579-585. 
17. Olatinwo, M.O. - Some stability results for nonexpansive and quasi-nonexpansive operators in uniformly convex Banach space using the Ishikawa iteration process, Carpathian J. Math., 24 (2008), 82-87.

18. Olatinwo, M.O. - Some results on multi-valued weakly Jungck mappings in b-metric space, Central European J. of Mathematics, 6 (2008), 610-621.

19. OrtegA, J.M.; Rheinboldt, W.C. - Iterative Solution of Nonlinear Equations in Several Variables, Academic Press, New York-London 1970.

20. PăCurar, M. - Sequences of almost contractions and fixed points, Carpathian J. Math., 24 (2008), 101-109.

21. PăCURAR, M. - A multi-step iterative method for approximating fixed points of Presić-Kannan operators, Acta Math. Univ. Comenian. (N.S.), 79 (2010), 77-88.

22. PĂCURAR, M. - Remark regarding two classes of almost contractions with unique fixed point, Creative Math. and Inf., 19 (2010), 178-183.

23. PĂCURAR, M. - Iterative Methods for Fixed Point Approximation, Risoprint, 2009.

24. Prasad, B.; Singh, B.; SAhni, R. - Some approximate fixed point theorems, Int. J. Math. Anal. (Ruse), 3 (2009), 203-210.

25. Presić, S.B. - Sur une classe d' inéquations aux différences finite et sur la convergence de certaines suites, Publ. Inst. Math. (Beograd)(N.S.), 5 (1965), 75-78.

26. Rus, I.A. - An iterative method for the solution of the equation $x=f(x, \ldots, x)$, Anal. Numér. Théor. Approx., 10 (1981), 95-100.

27. Rus, I.A. - An abstract point of view in the nonlinear difference equations, Analysis, functional equations, approximation and convexity (Cluj-Napoca, 1999), 272-276, Carpatica, Cluj-Napoca, 1999.

28. Stević, S. - Asymptotic behavior of a class of nonlinear difference equations, Discrete Dyn. Nat. Soc. 2006, Art. ID 47156, 10 pp.

29. Stević, S. - On the recursive sequence $x_{n+1}=A+x_{n}^{p} / x_{n-1}^{p}$, Discrete Dyn. Nat. Soc. 2007, Art. ID 40963, 9 pp.

Received: 18.X.2010

Revised: 13.I.2011

Revised: 24.I.2011
Facultatea de Ştiinţe Economice şi Gestiunea Afacerilor, Universitatea "Babeş-Bolyai" Cluj-Napoca, ROMANIA madalina.pacurar@econ.ubbcluj.ro 